\title{
Impact of Transformational Leadership on Employee's Job Satisfaction and Well-Being Through Team Efficacy in PMBMC
}

\author{
Inam Ullah Khan \\ Ph.D Scholar \\ National College of Business Administration and Economics, Lahore, Pakistan \\ E-mail: malikinamullahkhan@gmail.com
}

Dr. Syed Anwer Hasnain

Associate Professor

National College of Business Administration and Economics Lahore, Pakistan

E-mail: anwerleo@yahoo.com

Sami Ullah, Ph.D Scholar

National College of Business Administration and Economics, Lahore, Pakistan

E-mail: samiullahkhan124@gmail.com

Adeel Khalid, Ph.D Scholar

The University of Auckland, New Zealand

E-mail: a.khalid@auckland.ac.nz

Received: Jan. 22, 2018 Accepted: Feb. 24, 2018 Online published: Mar. 8, 2018

doi:10.5296/ijhrs.v8i1.12521 URL: https://doi.org/10.5296/ijhrs.v8i1.12521 


\section{Abstract}

The importance of transformational leadership and well-being of staff in the government punjab model bazaar management company (PMBMC) is progressively more recognized, anyhow there is a lesser amount of information regarding the mechanism to enlighten the relationship between transformational leadership (TFL) and employee job satisfaction (JS) and well-being (WB). The objective of this study is examining psychological mechanism that links with transformational leadership behaviors to employee's job satisfaction and well-being. The study design is cross sectional and take place in all (26) model bazaars in Punjab. 200 staff of PMBMC completed the survey questionnaire which was sent to all employees in each bazaar, all participants are males with average ratio of education intermediate and age average 27 to 35 years. Each participant would rate their line manager's leadership style. Team efficacy was found to act as mediator. In industries and commerce sector PMBMC pressurized environment faced by employees, today transformational leadership may help by ensuring employee's job satisfaction and positive state of mind as well-being in the form of competent group.

Keywords: transformational leadership (TFL), team efficacy (TE), well-being (WB), job satisfaction (JS)

\section{Introduction}

TFL has received increasing interest within the punjab government companies in pakistan, especially within PMBMC, and such type of leadership style has been promoted that will facilitate modify and boost the self-dedication to work, JS and WB within teams (Mohammed et al., 2010). Significant literature has established the links between TFL and a range of work outcomes, particularly JS and WB. However, little is known about the psychological mechanisms by which this connection occurs. The effectiveness or else confidence of the individual in his ability to do the job, is the possible mechanism explored here. It is hypothesized that leadership can exert influence through colleagues (team-efficacy) (mcIntyre \& foti, 2013). This study aims to explaining the relationship between TFL, WB and JS and TE as mediator between TFL and WB and also between TFL and JS.

\section{Research Hypotheses}

Keeping in view the scope of study, following research hypotheses are formulated:

H1: TFL will have a positive significant relationship with TE.

H2: TFL will have a positive significant relationship with WB.

H3: TFL will have a positive significant relationship with JS.

$\mathbf{H}_{\mathbf{4}}$ : TE will mediate the relationship between TFL and JS.

$\mathbf{H}_{\mathbf{4 b}}$ : TE will mediate the relationship between TFL and WB.

\section{Transformational Leadership}

The TFL theories have attained more research notice than all other types of leadership 
theories styles (aga et al., 2016). Transformational leaders falls in the statement of 'expand and raise the benefits of their group followers, raise the knowledge and promise of individuals in the group to the object and task of the group as mission, and allow their followers to go above their own benefits for the sake of perfection of the group' (barling et al., 2011). Such type of leaders make available or provide personal attention, encourage the developing individualized considerations, introduced the new ways of working within the team mates, encourage their members who provide the solutions to the innovative problems, and gave coaching and enhancing the intellectual simulation in the team members behaviors. Even the nature of the transformational leadership has increased more interest to be researched due to their dimensions, unfortunately less knowledge provided about the procedure by which transformational leadership give its possessions. The leaders which fall in the category of transformational leadership not transactional leadership go far for the mutual relations and boosted their team members to realize more than they thought that they cannot imagine (mcIntyre \& foti, 2013).

Different researchers use different types or dimensions of the transformational leadership for conceptualization and measurement, there is considerable overlap between them. A common conceptualization suggests that transformational leadership having four types of dimension: motivation of inspiration, intellectual stimulation, idealized influence and individual consideration (aga et al., 2016). The leaders motivated their follower through inspiration by having high expectations and encouragement to boost them through their thoughts. Encouraging team members to the challenge status quo to restrained and answer their own questions which influenced through the tacit knowledge, such motivation enhanced from the dimension of intellectual stimulation. Leaders mostly perform such work to perform right things phenomena and creating the trust between their team members and also making such environment where every one respect each other's, such dimension falls in the idealized influence. Finally, an individual of the team and leader itself considered all team members a person, they mostly spends time to guiding each other where anyone get problem and also gave appreciation for their achievements (Ng, T. W, 2017).

Transformational leadership style of the leader behavior effect the interest of the employees and also this style having a vital factor as viewed in the government sectors are one of the professions identified as particularly stressful. In pakistan, the main province punjab having a lot of government professions where particularly found such type of leadership style. In punjab, industries and commerce sector named as punjab model bazaar management company (PMBMC) are giving services to the public in their field work and in such field transformational leadership is play a major role to motivate, inspire and reduce the stress of their team members. In addition, the TFL style may be of picky importance in punjab, where new public administration strategies signify that all assistant bazaar managers are responsible for good governance and client satisfaction. As such assistant managers represent the connection between consumers and the bazaar system. A number of studies have reported strong associations between TFL style such as increased JS (Podsakoff et al., 1990; Morrison et al., 1997; Shieh et al., 2001; Bono and Judge, 2003; Berson and Linton, 2005), and lower levels of work related stress (Sosik and Godshalk, 2000). Fewer studies have examined the 
mechanisms that may help explain this association. Nielsen et al. (2008) found functioning characteristics to mediate the relationship between TFL and WB, but a lesser amount of research has inattentive on the psychological mechanism that can enlighten this connection, i.e. how TFL influence individuals' cognitions. Masa'deh et al., (2016) affirms that transformational leaders offer healthy work possible, especially in a team environment, increasing the logic of efficacy and control of supposed control, orientation of employee roles and influence high confidence level in management. By this, these psychological mechanisms will provide health outcomes such as advanced level of psychological well-being. This study provides a mutual understanding of the role of team efficacy as mediating effects with the relationship of TFL, WB and JS of the employee.

\section{Team Efficacy}

TE is the most suitable factor which enhances the abilities of the team members and also inspired them to achieve the task for the sake of team performance (Moghaddam et al., 2011). So each member recognizes the cognitive frameworks through different phenomena. In adding, the master of problem solving due to the high level of team efficacy and every member should participate in team works. Before joining the team, the sub ordinate should have the skills which are required to achieve the team goals depending on the bazaar situation. It is unclear what type of skills required for achieving these goals that will be stimulation through their leader. So that having grip in skills provide a positive impacts on job performance and job satisfaction as well. Those who have such skills grip with high level of efficacy are extra able to tolerate the difficult situations (mcIntyre \& foti, 2013). The organization of teamwork has been defended as a way to design work that can optimize customer service, especially in special day bazaar systems.

There is a growing awareness in teams that is achieving the beneficial effects of team work and also must be well practical ( $\mathrm{Ng}, \mathrm{T}$. W, 2017). The effectiveness of the team refers to the evaluation by the individuals of the collective capacity of the group or the team to systematize and to perform the courses of achievement. Team efficacy is not only the adding the effectiveness values of the each members of the team, the thought "can I do this task" (self-efficacy) totally different side as the thought formed in group which is "can we do this task" (team-efficacy). Involves efficacy in team having different interactions between the team members and mutual enhanced of the motivation, beliefs and performance of the team mates more enhancing result than the individual self-direction. The relationship between team efficacy and performance outcomes is well researched. For example, it has been found to forecast motivation (Gully et al., 2002); making goal commitment in to the employees (Moghaddam et al., 2011); and employee training and team performance evaluation (Nasra et al., 2016). There is less research that TE is linked with JS. The effectiveness of the team was linked with the results, as well as JS and turnover intentions. On the other hand, the correlates of the efficiency and well-being of the team are less known.

According to kark and shamir (2002) TFL can lead to TE during the process of inspirational, motivational and encouraging the members in the team, Also recognize the contributions by members and tasks performance and encouragement of team members to move closer to the 
goals target through leadership capabilities. In the study of chen and lee (2007), found that transformational leadership improves the team collective efficacy. From the study of walumbwa et al., (2004) predicted that TE was found as partially mediated between satisfaction and commitment and transformational leadership. So, less is known about the relationship of TFL and WB role in the team work. In addition, TE and TFL, JS and WB not been explored. By considering the TE mechanism of the team, it will be improved able to increase effectiveness in place of work and to propose targeted interventions in an appropriate manner at the team or leadership mechanism. This research aims to fill this space.

\section{Conceptual Framework}

To recap, prior research on transformational leadership with the relationships of self-efficacy has been done and also seeing TFL with job satisfaction and company staff well-being. However, no studies have yet found and investigated the relationships of transformational leadership by mediated efficacy of the team. For the relationship of variables TFL with JS and employee WB been understand, it is essential to recognize the relationship with the psychological mechanism and its importance. Transformational leadership is the assessment of the individual abilities enhanced through idealized and other dimensions by their leaders (Thompson, 2012). For this followers can easily cope their challenges by using their skills, in return they get satisfaction and goodness in its self. So we predict that TFL also linked to how employee perceives their team members. A strong TE also contributes the positive sense in the interpersonal climate and greater correspondence and hence higher levels of WB and JS among followers. In health care centers number of studies provides importance to the team work environment (West et al., 2002). So in this research examine the transformational leadership with the linked of cognitive evaluation of team efficacy. This study explores to construct hypotheses on the basis of prior research. Four types of hypotheses derived on the basis of previous research.

The relationships between variables summarized in Fig. 1.

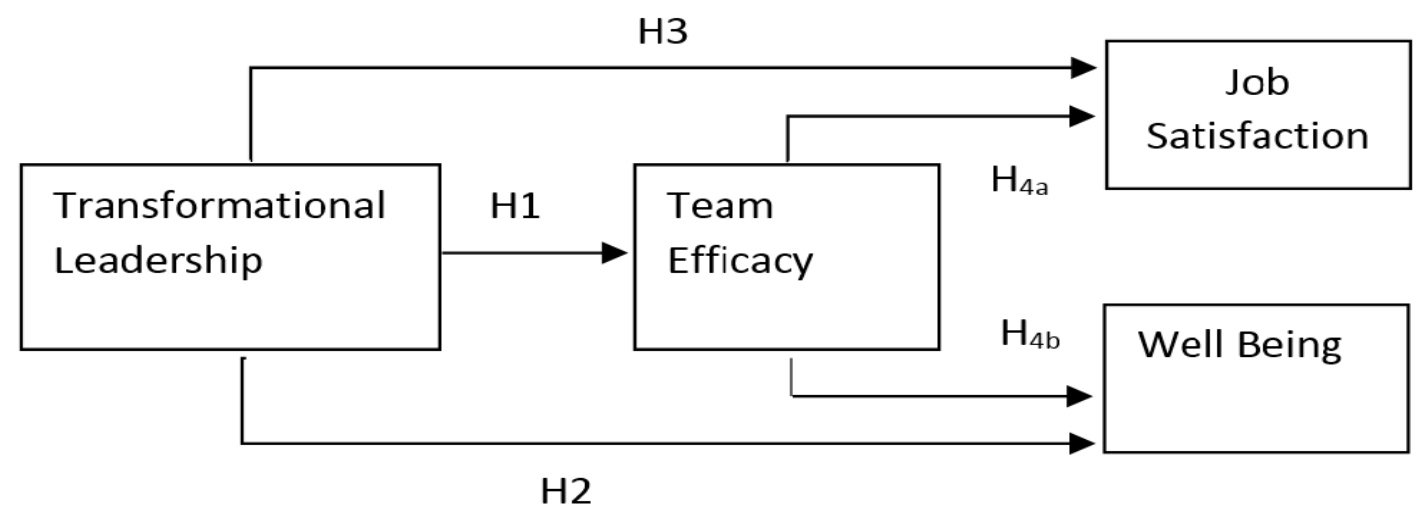

Fig. 1

\section{Design and Procedure}

A survey questionnaire have been distributed among all members of staff in PMBMC and 
where management staff were asked to rate their manager's leadership style and were asked to evaluate their own level of efficacy in their team (TE) and their JS and psychological WB. The design of the survey used cross sectional questionnaire design, only one time data collected. Participants working in PMBMC were asked questions about their TE, WB and asked to rate their manager (line manager) on a variety of leadership (TFL) behavior. There are two types of leadership styles transactional and transformational but in our study transformational leadership styles enhanced more due to the more possibility appearance in PMBMC because the manager at this level shows such type of leadership commands to their followers (Bass, 1999).

\section{Participants}

The employees working in the government punjab all model bazaar management company (PMBMC) consisted as sample. There are 26 total numbers of bazaars of PMBMC in Punjab, total staff participation members were above 541 but actual participants were 200 who have attempted the survey questionnaire. Staff included cleaning personnel, Gardener personnel, Security personnel, parking personnel, Electrical personnel, special day bazaar contractors, joy land contractors, Cashiers and assistant manager's staff. These staff members was participated and asked questionnaire regarding the study conduct.

\section{Transformational Leadership}

There are two types of leadership styles transactional and transformational but in our study transformational leadership style enhanced more due to the more possibility appearance in PMBMC because the manager at this level shows such type of leadership commands to their followers. So TFL Scale consisted seven items scale developed and taken from Carless et al. (2000). An item example is: "my leader encourages thinking about problems in new ways and questions assumptions". Responses to these categories were: The response categories were " 1 = Never, 2 = Almost never, 3 = Sometimes, $4=$ Often, $5=$ Very often, $6=$ Always".

\section{Team Efficacy}

A scale with for items is used and driven from Salanova et al. (2003). An example of an item is: "my group is able to solve difficult tasks if we invest the necessary effort". Response categories to these items were: " $1=$ Never, $2=$ Almost never, $3=$ Sometimes, $4=$ Often, $5=$ Very often, 6 = Always".

\section{Well-Being}

The WB scale is to measure the employees been in a positive state of mind, like happy and energetic. An item example is: "In most ways my life is close to my ideal". The response categories were " 1 = Never, $2=$ Almost never, $3=$ Sometimes, $4=$ Often, $5=$ Very often, $6=$ Always". (Diener et al., 1985).

\section{Job satisfaction}

The scales were taken from the Kristensen et al., (2006). An example of an item is: "Do you have the possibility of learning new things through your work?" The response categories were 
“ 1 = Never, 2 = Almost never, $3=$ Sometimes, $4=$ Often, $5=$ Very often, $6=$ Always".

Table 3.1. Summary of Scales

\begin{tabular}{c|c|c}
\hline Variable & Author & No of items \\
\hline Transformational Leadership & Carless et al. (2000) & 7 \\
\hline Team Efficacy & Salanova et al. (2003) & 4 \\
\hline Well being & Diener et al. (1985) & 5 \\
\hline Job Satisfaction & Kristensen et al. (2006) & 5 \\
\hline
\end{tabular}

\section{Data Analysis}

Demographic characteristics of the respondents age of 56.0\% respondents was 27-35 years, $20.5 \%$ respondents was $18-25,12.5 \%$ respondents was $36-45,11.0 \%$ respondents was above 45 age and gender of all respondents were males. The education of $6 \%$ respondents was master, 36\% respondents was bachelor, $42 \%$ respondents were intermediate which highest ratio amongst was, and $16 \%$ respondents were metric. Reliability of the scale was checked by using cronbach alpha technique. Alpha reliabilities of all variables as shown in table 4.2. were well above .70 (> 0.70, kline, 2005), that proves data obtained was reliable enough to proceed for further analysis.

\section{Results}

Table 4.1. describes means, standard deviations and correlations among the study variables. Multicollinearity was not issue, because correlation analysis showed that correlation coefficients were lower (<0.70; Tabachnick \& Fidell, 1996).

Table 4.1. Correlations

\begin{tabular}{c|c|c|c|c|c|c|c|c|c}
\hline Variables & Mean & SD & Alpha & 1 & 2 & 3 & 4 & 5 & 6 \\
\hline $\begin{array}{c}\text { Education of the } \\
\text { staff }\end{array}$ & 2.32 & .813 & - & 1 & & & & & \\
\hline Age of the staff & 2.14 & .868 & - & $-.270^{* *}$ & 1 & & & & \\
\hline $\begin{array}{c}\text { Transformational } \\
\text { Leadership }\end{array}$ & 5.2121 & .70873 & 0.889 & $-.156^{*}$ & .058 & 1 & & & \\
\hline Team Efficacy & 5.1888 & .66805 & 0.814 & -.121 & .138 & $.629^{* *}$ & 1 & & \\
\hline Well being & 5.1850 & .74238 & 0.835 & $-.285^{* *}$ & .003 & $.687^{* *}$ & $.606^{* *}$ & 1 & \\
\hline Job Satisfaction & 5.1900 & .73635 & 0.836 & $-.273^{* *}$ & .018 & $.690^{* *}$ & $.609^{* *}$ & $.995^{* *}$ & 1 \\
\hline
\end{tabular}

**. Correlation is significant at the 0.01 level (2-tailed).

As shown in table 4.1. Transformational leadership is significantly correlated with team efficacy $(\mathrm{r}=.629, p<.01)$, well-being $(\mathrm{r}=.687, p<.01)$, and job satisfaction $(\mathrm{r}=.690, p$ $<.01)$. Team efficacy is significantly correlated with well-being $(\mathrm{r}=.606, p<.01)$ and job satisfaction $(\mathrm{r}=.609, p<.01)$. Well-being is significantly correlated with job satisfaction $(\mathrm{r}$ $=.995, p<.01)$.

\section{Regression Analysis}

By applying the process of Andrew F, Hayes to check the mediation. First keeping mediator team efficacy (TE) as dependent and transformational leadership (TFL) as independent to check the relationship. In table 4.2. result shows that $\mathrm{p}$ value is less than 0.05 which shows 


\section{Ml Macrothink}

International Journal of Human Resource Studies ISSN 2162-3058 2018, Vol. 8, No. 1

that there is significant relationship between TFL and TE. The coefficient value is .5927 which shows that there is positive correlation between TFL and TE. Additionally, one unit change in TFL causes .5927 unit changes in TE it means that if TFL increase than TE also increases.

Table 4.2. TE as outcome variable

\begin{tabular}{c|c|c|c|c}
\hline & Coefficient & P & LLCI & ULCI \\
\hline Constant & 2.0997 & .0000 & 1.5594 & 2.6400 \\
\hline TFL & .5927 & .0000 & .4899 & .6954 \\
\hline R-sq & .6288 & & & \\
\hline p-value & .0000 & & & \\
\hline
\end{tabular}

Second step in process of Andrew F, Hayes is that to check the overall effect of TFL and TE on Well-being (WB) and also check the direct relation of TFL and WB. The WB is the outcome variable shown in table 4.3.

Table 4.3. WB as outcome variable

\begin{tabular}{c|c|c|c|c}
\hline & Coefficient & P & LLCI & ULCI \\
\hline Constant & .7654 & .0142 & .1556 & 1.3752 \\
\hline TE & .3195 & .0000 & .1806 & .4584 \\
\hline TFL & .5299 & .0000 & .3990 & .6608 \\
\hline Direct effect of X on Y & Effect & P & LLCI & ULCI \\
\hline Indirect effect of X on Y & .5299 & .0000 & .3990 & .6608 \\
\hline Effect & Boot LLCI & Boot ULCI & \\
\hline R-sq & .1894 & .0891 & .3256 & \\
\hline p-value & .5215 & & & \\
\hline
\end{tabular}

So using WB as dependent variable and checked the combine effect of TFL and TE on WB. Result shows that the TE and TFL both significantly related with WB because both p-values are below from 0.05 . The coefficient value of TE is .3195 which shows that there is a positive correlation between TE and WB and change in one unit of TE causes changes .3195 unit changes in WB. As TFL coefficient values shows that there is also positive correlation between TFL and WB and one unit change in TFL causes .5299 unit change in WB. Moreover, the direct relation shows that, there is direct relation exist between independent and dependent variable and indirect effect shows that there is significant indirect relationship also exist. It means the TE causes mediation between TFL and WB. So above the result and explanation is concluded that independent and dependent variable having direct and indirect significant relation, which means the TE is partially mediates the TFL and WB. So our H1, $\mathrm{H} 2$ and $\mathrm{H} 4 \mathrm{~b}$ accepted with the support of the results.

For checking the next path of mediation through applying the process of Andrew F, Hayes, according to the table the mediator team efficacy (TE) as dependent and transformational leadership (TFL) as independent relationship to check. In table 4.4. result shows that TFL and TE, $\mathrm{p}$ value is less than 0.05 which shows that there is significant relationship between TFL and TE. The coefficient value is .5927 which shows that there is positive correlation between TFL and TE. Additionally, one unit change in TFL causes .5927 unit changes in TE it means that if TFL increase than TE also increases. 
Table 4.4. TE as outcome variable

\begin{tabular}{c|c|c|c|c}
\hline & Coefficient & P & LLCI & ULCI \\
\hline Constant & 2.0997 & .0000 & 1.5594 & 2.6400 \\
\hline TFL & .5927 & .0000 & .4899 & .6954 \\
\hline R-sq & .3953 & & & \\
\hline p-value & .0000 & & & \\
\hline
\end{tabular}

Second step in process of Andrew F, Hayes is that to check the overall effect of TFL and TE on Job Satisfaction (JS) and also check the direct relation of TFL and JS. The WB is the outcome variable shown in table 4.5 .

Table 4.5. JS as outcome variable

\begin{tabular}{c|c|c|c|c}
\hline & Coefficient & P & LLCI & ULCI \\
\hline Constant & .7839 & .0109 & .1825 & 1.3853 \\
\hline TE & .3183 & .0000 & .1813 & .4553 \\
\hline TFL & .5285 & .0000 & .3993 & .6576 \\
\hline Direct effect of X on Y & Effect & P & LLCI & ULCI \\
\hline & .5285 & .0000 & .3993 & .6576 \\
\hline Indirect effect of X on Y & Effect & Boot LLCI & Boot ULCI & \\
\hline R-sq & .1887 & .0873 & .3211 & \\
\hline p-value & .7258 & & & \\
\hline & .0000 & & & \\
\hline
\end{tabular}

So using JS as dependent variable and checked the combine effect of TFL and TE on JS. Result shows that the TE and TFL both significantly related with JS because both p-values are below than 0.05 . The coefficient value of TE is .3183 which shows that there is a positive correlation between TE and WB and change in one unit of TE causes changes .3183 unit changes in JS. As it is the TFL coefficient values is also positive correlation between TFL and JS and one unit change in TFL causes .5285 unit change in JS. Moreover, the direct relation shows that, there is direct relation exist between independent and dependent variable and indirect effect shows that there is significant indirect relationship also exist. It means the TE causes mediation between TFL and JS. So above the result and explanation is concluded that independent and dependent variable having direct and indirect significant relation, which means the TE is partially mediates the TFL and JS. So our H1, H3 and H4a accepted with the support of the results.

\section{Discussion}

These findings of our study link between TFL, JS, WB and TE support the previous research and increase our understanding of direct relationship of TFL to the JS, WB and TE too. Four key findings are elaborated: First, direct associations of TE with JS and WB were found (Thomas, 2003) and further, demonstrate the TE importance in PMBMC setting. Second, TFL having direct relationship with TE identified in this study (walumbwa et al., 2004). Third, the relationship between TFL and JS was found to be partially mediated by TE, furthermore the relationship between TFL and WB was found to be partially mediated by TE. This finding suggests that TFL exerts its effect on JS and WB through the mechanism of TE. As new insights gives how teams are working to be competent, skilled to tackle the problems and accepting the new challenges as a volunteer's. High level of efficacy in teams may low the 
deficiency in individual team members which showing low efficacy. The team members are skilled and competent to take the new challenges and also resolve problems through their capabilities then individual high levels of JS allowing them to identify their team members. The employees of PMBMC feel there self are the part of such team which are high motivated, skilled to perform new tasks by accepting the challenges in the stressful environment, that type of feel automatically feel them satisfied from their job and our results also support the importance of PMBMC team work.

\section{Limitation}

Certain limitations must be taken into account when interpreting our results. First, the study is inspired by the paradigm of TFL. TFL is a useful, but not exhaustive, narrative of the leadership style. Our study used a broad but reliable and valid measure of TFL to test the validity of mediated relationships. The measure chosen was well adapted to a studied population: it was estimated that a long questionnaire would have a negative influence on the response rates without causing substantial gains of reliability and validity. In future research, it would be interesting to examine the role of other dimensions of leadership, for example, to determine whether transactional styles have direct effects on efficiency and WB. Second, the data presented are cross-sectional, and subsequently we cannot comment on causality. By relying on longitudinal designs and employee leadership dyads can help better understand the direction of relationships between TFL, TE provide further support of these complex relationships.

\section{Implication}

In the changing and stressful environment in which PMBMC management maintaining their work and improving the levels of JS and WB which is the key objective for all government sectors in sense of services. From this study, the TFL was associated with JS and WB at work, transformational style should encourage managers to adopt this style (i.e. work to establish a shared vision through which leaders give meaning and creativity). Prior research studies have confirmed that TFL style behaviors formed and it would then be interesting to examine how changes in the TFL have an impact on effectiveness (Bass, 1985). The results of this study highlight the need for caution: exercise behaviors associated with TFL (such as stimulating employees to make difficult decisions and problem solving, mentoring individuals, coaching and providing clear vision, Etc.) Can short term lead to increase the well-being of their disciples, but only if their behavior changes the way the disciples perceive themselves.

\section{Conclusion}

This study discusses the advantages of transformational leadership (TFL) and the mediating role of team efficacy (TE) with TFL, WB and JS. The employees of PMBMC rate their manager's leadership style with the Job satisfaction, well-being and team efficacy as a intervening variable. A good and effective manager should have the following capabilities like active listening abilities, questioning skill, observation, quick feedback, directness of new thoughts, several viewpoints in decision making, reasoning, logical skills, flexibility, 
open communication, clarification of goals and strategies, teamwork, interviewing skills, and forming a helpful atmosphere. Managers should provide clear objectives and means; provide instant feedback for performance improvement, role modeling and useful instructions, on-the-job opportunities for employees to learning and development, appreciation and compensation, and facilitating employee's development and success for enhancing in-role performance. (Kim et al., 2013). In this study it is found that there is a direct relationship between TFL to JS, WB and indirect through TE. So it means that TE partially mediating the relationship between TFL and JS and also between TFL and WB. This means our all hypotheses are accepted with our results generated through process analysis.

\section{References}

Aga, D. A., Noorderhaven, N., \& Vallejo, B. (2016). Transformational leadership and project success: The mediating role of team-building. International Journal of Project Management, 34(5), 806-818. https://doi.org/10.1016/j.ijproman.2016.02.012

Barling, J., Christie, A., \& Hoption, A. (2011). Leadership. In S. Zedeck (Ed.), Handbook of industrial and organizational psychology. Washington, DC: American Psychological Association. https://doi.org/10.1037/12169-007

Bass, B. M. (1985). Leadership Beyond Expectations. Free Press, New York.

Bass, B. M. (1999). Two decades of research and development in transformational leadership. European Journal of Work and Organizational Psychology 8, 9-32. https://doi.org/10.1080/135943299398410

Berson, Y., \& Linton, J. (2005). An examination of the relationships between leadership style, and employee satisfaction in $\mathrm{R} \& \mathrm{D}$ versus administrative environments. $R \& D$ Management 35, 51-60. https://doi.org/10.1111/j.1467-9310.2005.00371.x

Bono, J. E., \& Judge, T. A. (2003). Self-concordance at work: toward understanding the motivational effects of transformational leaders. Academy of Management Journal 46, 554-571. https://doi.org/10.2307/30040649

Carless, S., Wearing, A., \& Mann, L. (2000). A short measure of transformational leadership. Journal of Business and Psychology 14, 389-405. https://doi.org/10.1023/A:1022991115523

Chen, C. H. V., \& Lee, H. M. (2007). Effects of transformational team leadership on collective efficacy and team performance. International Journal of Management and Enterprise Development 4, 202-217. https://doi.org/10.1504/IJMED.2007.011792

Diener, E., Emmons, R. A., Larsen, R. J., \& Griffin, S. (1985). The Satisfaction with Life $\begin{array}{lllll}\text { Scale. Journal of Personality } & \text { Assessment, } & \text { 49, }\end{array}$ https://doi.org/10.1207/s15327752jpa4901_13

Gully, S. M., Incalcaterra, K. A., Joshi, J. M., \& Beaubien, J. M. (2002). A metaanalysis of team-efficacy, potency, and performance: interdependence and level of analysis as moderators of observed relationships. Journal of Applied Psychology 87, 819-835. https://doi.org/10.1037/0021-9010.87.5.819 
Kark, R., \& Shamir, B. (2002). The influence of transformational leadership on followers' relational versus collective self-concept. In: Academy of Management Proceedings.

Kim, S., Egan, T. M., Kim, W., \& Kim, J. (2013). The impact of managerial coaching behavior on employee work-related reactions. Journal of Business and Psychology, 28(3), 315-330. https://doi.org/10.1007/s10869-013-9286-9

Kline, R. B. (2005). Principles and practice of structural equation modeling. New York, NY: Guilford Press.

Kristensen, T., Hannerz, H., Hogh, A., \& Borg, V. (2006). The Copenhagen Psychosocial questionnaire (COPSOQ). A tool for the assessment and improvement of the psychosocial work environment. Scandinavian Journal of Work and Environmental Health 31, 438-449. https://doi.org/10.5271/sjweh.948

Masa'deh, R. E., Obeidat, B. Y., \& Tarhini, A. (2016). A Jordanian empirical study of the associations among transformational leadership, transactional leadership, knowledge sharing, job performance, and firm performance: A structural equation modelling approach. Journal of Management Development, 35(5), 681-705. https://doi.org/10.1108/JMD-09-2015-0134

McIntyre, H. H., \& Foti, R. J. (2013). The impact of shared leadership on teamwork mental models and performance in self-directed teams. Group Processes \& Intergroup Relations, 16, 46-57. https://doi.org/10.1177/1368430211422923

Moghaddam A. Z., Ghanbari, A., \& Hosseinzadeh, A. (2011) Relationship between the Leadership Method and Self Efficacy of the Staff. American Journal of Scientific Research $40,160-172$.

Mohammed, S., Ferzandi, L., \& Hamilton, K. (2010). Metaphor no more: A 15 year review of the team mental model construct. Journal of Management, 36, 876-910. https://doi.org/10.1177/0149206309356804

Morrison, R., Jones, L., Fuller, B., (1997). The relation between leadership style and empowerment on satisfaction of nurses. Journal of Nursing Administration 27, 27-34. https://doi.org/10.1097/00005110-199705000-00007

Nasra, M. A., \& Heilbrunn, S. (2016). Transformational leadership and organizational citizenship behavior in the Arab educational system in Israel: The impact of trust and job satisfaction. Educational Management Administration \& Leadership, 44(3), 380-396. https://doi.org/10.1177/1741143214549975

Ng, T. W. (2017). Transformational leadership and performance outcomes: Analyses of multiple mediation pathways. The Leadership Quarterly, 28(3), 385-417. https://doi.org/10.1016/j.leaqua.2016.11.008

Nielsen, K., Randall, R., Yarker, J., Brenner, S. O. (2008a). The effects of transformational leadership on followers' perceived work characteristics and psychological well-being: A longitudinal study. Work \& Stress 22(1), 16-32. https://doi.org/10.1080/02678370801979430 


\section{Macrothink}

International Journal of Human Resource Studies

ISSN 2162-3058

2018, Vol. 8, No. 1

Podsakoff, P. M., MacKenzie, S., Moorman, R., \& Fetter, R. (1990). Transformational leader behaviors and their effects on followers' trust in their leader, satisfaction, and organizational citizen behaviors. Leadership Quarterly 1, 107-142. https://doi.org/10.1016/1048-9843(90)90009-7

Salanova, M., Llorens, S., Cifre, E., Martı'nez, I., \& Schaufeli, W. (2003). Perceived collective efficacy, subjective well-being and task performance among electronic work groups. Small Group Research 34, 43-73. https://doi.org/10.1177/1046496402239577

Schaubroeck, J., Lam, S. S. K., \& Peng, A. C. (2011). Cognition based and affect based trust as mediators of leader behavior influences on team performance. Journal of Applied Psychology, 96, 863-871. https://doi.org/10.1037/a0022625

Shieh, H. L., Mills, M. E., \& Waltz, C. E. (2001). Academic leadership style predictors for nursing faculty job satisfaction in Taiwan. Journal of Nursing Education 40, 203-209.

Sosik, J., \& Godshalk, V. (2000). Leadership styles, mentoring functions received, and job-related stress: a conceptual model and preliminary study. Journal of Organizational Behavior 21, 365-390. https://doi.org/10.1002/(SICI)1099-1379(200006)21:4<365::AID-JOB14>3.0.CO;2-H

Tabachnick, B. G., \& Fidell, L. S. (1996). Using Multivariate Statistics. Harper Collins, New York.

Thompson, J. (2012) Transformational leadership can improve workforce competencies. Nursing Management 18(10), 21-24. https://doi.org/10.7748/nm2012.03.18.10.21.c8958

Walumbwa, F., Wang, P., Lawler, J. J., \& Shi, K. (2004). The role of collective efficacy in the relations between transformational leadership and work outcomes. Journal of Occupational and Organizational Psychology 77, 515-530. https://doi.org/10.1348/0963179042596441

West, M. A., Borrill, C., Dawson, J., Scully, J., Carter, M., Anelay, S., Patterson, M., \& Waring, J. (2002). The link between the management of employees and patient mortality in acute hospitals. International Journal of Human Resource Management 13, 1299-1310. https://doi.org/10.1080/09585190210156521

\section{Copyright Disclaimer}

Copyright for this article is retained by the author(s), with first publication rights granted to the journal.

This is an open-access article distributed under the terms and conditions of the Creative Commons Attribution license (http://creativecommons.org/licenses/by/4.0/). 